\title{
Double Plantaris Muscle: A Cadaveric Study with Clinical Importance
}

\author{
Músculo Plantar Doble: Un Estudio en Cadáver y su Importancia Clínica \\ Kum Kum Rana; Srijit Das \& Ranjana Verma
}

RANA, K.; DAS, S. \& VERMA, R. Double plantaris muscle: A cadaveric study with clinical importance. Int. J. Morphol., 24(3):495498, 2006.

SUMMARY: The gastrocnemius, plantaris and the soleus muscles, comprise the posterior (flexor) compartment muscles of the leg. The plantaris muscle is responsible for causing plantar flexion of the foot. The muscle is vestigial in human beings and has much clinical importance. The muscle is known to exhibit variations but there are few reports on the existence of double plantaris muscle. The present case report describes double plantaris on both sides of a cadaver, which was detected during routine dissection. Knowledge of both normal and abnormal anatomy of the plantaris muscle is important for surgeons performing tendon transfer operations and clinicians diagnosing muscle tears.

KEY WORDS: Plantaris muscle; Anatomical variation.

\section{INTRODUCTION}

The plantaris muscle is considered to be a flexor group muscle of the lower leg. The muscle originates from the lower part of the lateral supracondylar line and the oblique popliteal ligament (Standring, 2005). The muscle belly is fusiform in shape and the it ends as a long slender tendon which traverses obliquely between the gastrocnemius and the soleus muscles to fuse or insert with it (Standring). The muscle is also reported to merge with the flexor retinaculum or with the superficial fascia of the leg (Standring).

Standard textbooks mentions the fact that the muscle may be absent in $10 \%$ cases or may be double, but not much literature is available in this regard (Standring). The tendon of plantaris muscle serves as an excellent graft. The anatomical knowledge of plantaris muscle is also important for clinical diagnosis of the muscle rupture and interpreting MRI scans.

\section{CASE REPORT}

During routine dissection of cadavers for undergraduate medical teaching program, we detected double plantaris muscle on both sides of a 45 year male cadaver.
The muscle was displayed by careful dissection and delineation of surrounding structures. Morphometric measurements were taken and the specimen was photographed.

\section{OBSERVATIONS}

Right leg (Fig.1). Outer belly. The long outer belly was thicker ('B' in Fig.1) and much fleshy. It arose from lower part of lateral extension of linea aspera, above the origin of the lateral head of gastrocnemius muscle. It measured about 4" in length. It fused with the lateral side of common tendon of gastrocnemius and soleus muscles about a little below the middle of the leg. Thus, it failed to reach the heel.

Inner belly. The thinner inner belly arose from the fascia covering the popliteus medial to the origin of lateral head of gastrocnemius muscle ( $A$ ' in Fig.1) and was 2" in length. The tendon descended between the gastrocnemius and soleus muscles and was found to lie medial to the tendo calcaneus to be inserted into the small tuberosity on superior surface of calcaneum. 
Relations to other structures: The inner belly of the muscle crossed the tibial nerve as it descended between the gastrocnemius and the soleus muscles (' $D$ ' in Fig. 1). The popliteal artery was found to lie medial to both the bellies ('F' in Fig.1).

The nerve to inner belly of the plantaris muscle was in found in common with the nerve innervating the lateral

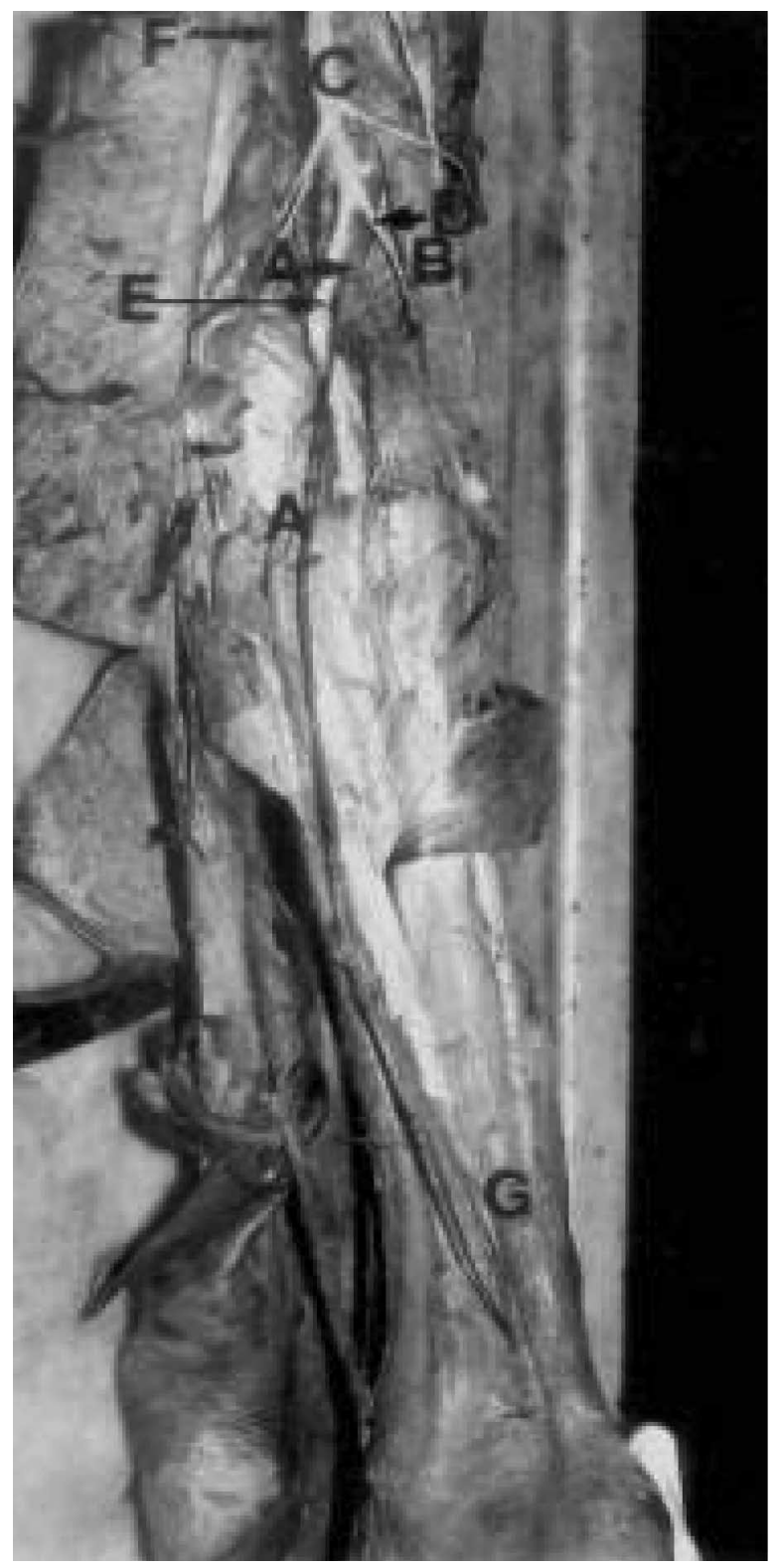

Fig. 1. Photograph of dissected specimen of right leg. A. Inner belly and tendon of plantaris; B. Outer belly of plantaris; C. Sciatic nerve; D. Common fibular nerve; E. Tibial nerve; F. Popliteal artery. G. Tendo calcaneus. head of the gastrocnemius muscle. The nerve supply to the inner belly was from a separate branch from nerve to lateral head of the gastrocnemius muscle. The nerve supply to the outer belly was in common with the nerve to the lateral head of gastrocnemius muscle.

Left leg (Fig. 2). Outer belly. In the left leg the outer belly was thick, fleshy and 5" long ('A' in Fig.2). It arose

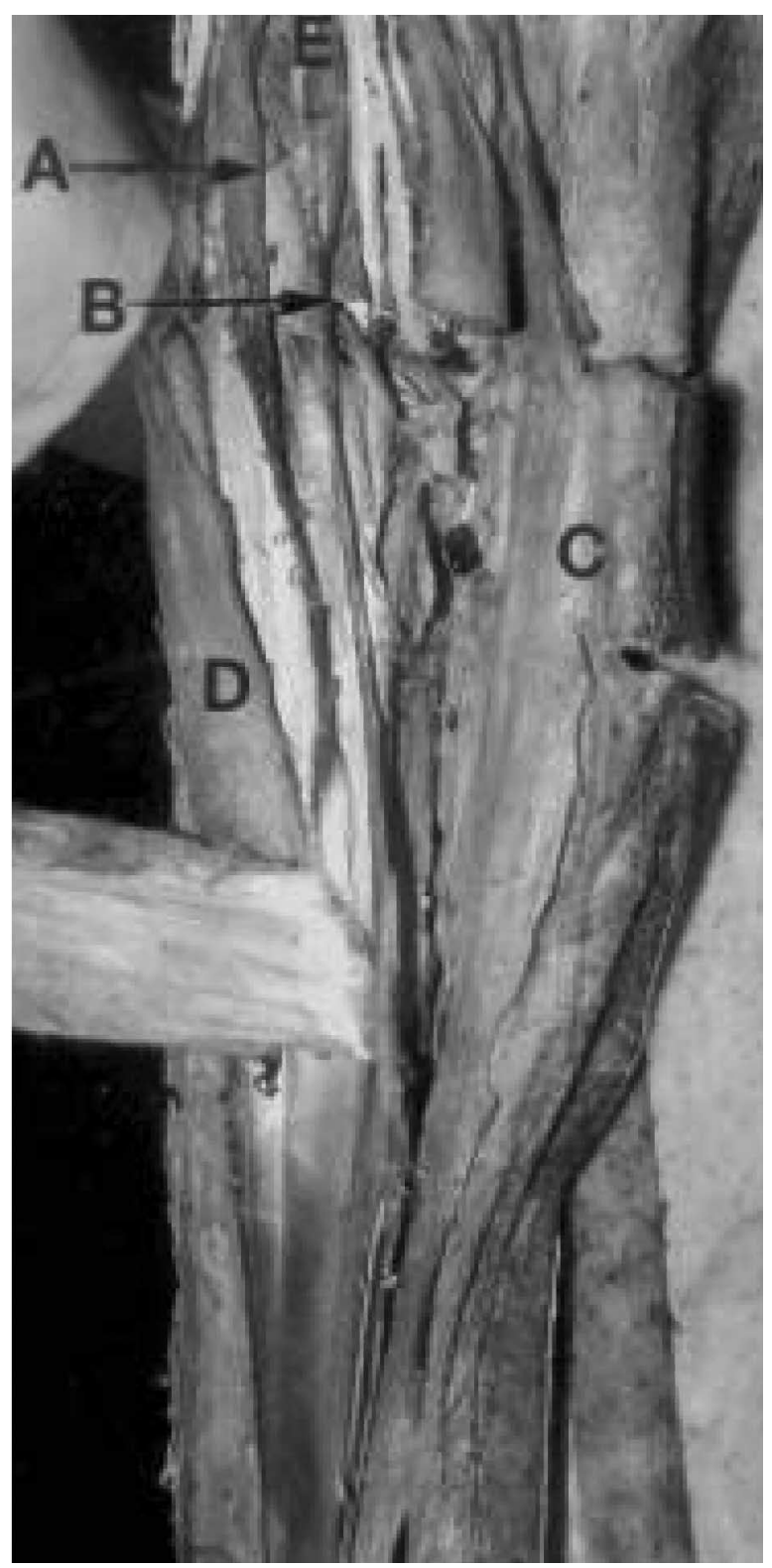

Fig. 2. Photograph of dissected specimen of left leg. A. Outer fleshy belly of plantaris; B. Inner belly of plantaris muscle continuing as tendon; C. Gastrocnemius muscle (medial head); D. Gastrocnemius muscle (lateral head); E. Sciatic nerve. 
from the lower end of lateral lip of linea aspera above the origin of lateral head of gastrocnemius muscle (from lateral supracondylar ridge). The tapering belly fused with the soft tissue between the muscle bellies of gastrocnemius and soleus muscles laterally below the middle of leg.

Inner belly.The inner belly was thinner of the two and measured 2" in length ('B' in Fig. 2). It arose from the posterior ligament of the knee at the inter condylar area. Few fibers seem to arise from the lower part of the lateral supracondylar ridge. It was crossed by nerve to lateral head of gastrocnemius muscle near its origin. The belly and its tendon passed between gastrocnemius and the soleus muscles from lateral to medial side and fused with the crural fascia just above the calcaneum.

Relations to other structures: The nerve to lateral head of the gastrocnemius muscle crossed the inner belly. The tibial nerve was found to lie medial to inner belly (' $E$ ' in Fig. 2). Popliteal artery was found to lie medial to the inner belly. The nerve supply to the outer belly was twig from the nerve to lateral head of gastrocnemius muscle. The inner belly got a separate twig from the nerve to lateral head of gastrocnemius muscle.

\section{DISCUSSION}

The plantaris muscle is known to exhibit variations. Standard textbook of anatomy has reported the fact, that the muscle may be sometimes absent or it may be double (Standring). It has been considered that the plantaris muscle was earlier attached to the plantar aponeurosis of the foot but with normal evolutionary process of erect posture, the insertion of the muscle got shifted to a higher position (Daseler \& Anson , 1943). In some animals like the American bear, the plantaris muscle can be found to be attached to the plantar aponeurosis (Daseler \& Anson).
The fusiform belly of the muscle has a long slender tendon which may be mistaken as a nerve. Often, the tendon of the plantaris muscle fuses superficially with the fascia of the leg, thereby making it vulnerable to injury. Topographical anatomy of the plantaris muscle is important for any surgery. Prior knowledge of superficial position of the tendon and its resemblance to a nerve should be borne in mind by any surgeon operating on the back of leg.

The plantaris muscle may be injured during any tear and proper diagnosis may be made only after obtaining a MRI scan or ultrasound. The tendinous injury of the plantaris muscle is important since it is associated with hemorrhage and edema (Deutsch \& Mink, 1989). The rupture of the tendon of the plantaris muscle is often difficult to diagnose and an important finding is the presence of a tense mass between the gastrocnemius and the soleus muscle (Allard et al., 1992).

The plantaris muscle has been used as an excellent graft (Simpson et al.,1991). Studies have described anatomical procedure of using a free plantaris tendon graft for reconstruction of the anterior talofibular and calcaneofibular ligaments ( Pagenstert et al., 2005). In the presence of other flexors like gastrocnemius and soleus muscles, the removal of plantaris muscle may not have an effect on the normal limb function. The tendon of the plantaris muscle is considered as an extremely tensile structure and has been used successfully for flexor tendon replacement in hand and even for atrioventricular valve repair (Shuhaiber et al., 2003).

Considering the above facts, the existence and importance of the plantaris muscle cannot be undermined. The presence of double plantaris muscle as seen in the present case may be of academic interest as the standard textbook of anatomy mentions less about this fact. It may also be of surgical interest to surgeons and clinical interest to clinicians diagnosing muscle tears in the leg.

RANA, K.; DAS, S. \& VERMA, R. Músculo plantar doble. Un estudio en cadáver y su importancia clínica. Int. J. Morphol., 24(3):495498, 2006.

RESUMEN: Los músculos gastronecmio, plantar y sóleo pertenecen al grupo de músculos flexores del compartimiento posterior de la pierna. El músculo plantar es reponsable de la flexión plantar del pie. El músculo es un vestigio en el humano y tiene gran importancia clínica. Se sabe que el músculo plantar tiene muchas variaciones, pero hay pocos repórters sobre la existencia de músculos plantares dobles. El presente trabajo describe un músculo plantar doble en ambos lados, presente en un cadáver, encontrado durante una disección de rutina. El conocimiento del músculo plantar, ya sea normal como de sus variaciones anatómicas, son importantes para el cirujano cuando éste transfiere tendones y para el clínico en el diagnóstico de ruptura muscular.

PALABRAS CLAVE: Músculo plantar; Variación anatómica. 


\section{REFERENCES}

Allard, J.C: Bancroft, J \& Porter, G. Imaging of plantaris muscle rupture. Clin. Imag., 16: 55-8, 1992.

Daseler, E. H. \& Anson, B. J. The plantaris muscle. J. Bone. Joint. Surg., 25:822-7, 1943.

Deutsch, A. L. \& Mink, J. H. Magnetic resonance imaging of musculoskeletal injuries. Radiol. Clin. North. Am., 27:983-1002, 1989.

Pagenstert, G. I. ; Valderrabano, V. \& Hintermann, B. Lateral ankle ligament reconstruction with free plantaris tendon graft. Techniques in Foot \& Ankle Surgery., 4:104$12,2005$.

Shuhaiber, J. H. \& Shuhaiber, H. H. Plantaris tendon graft for atrioventricular valve repair. A novel hypothetical technique. Tex. Heart. Inst. J., 30:42-4, 2003.

Simpson, S. L. ; Hertzog, M. S. \& Barja, R. H. The plantaris tendon graft: an ultrasound study. J. Hand Surg. [Am]., 16:708-11, 1991.

Standring Susan. Gray's Anatomy. The Anatomical Basis of Clinical Practice. $39^{\text {th }}$ ed. Elsevier Churchill Livingstone, Philadelphia, 2005. pp. 1499-500.
Correspondence to:

Dr. Kum Kum Rana, $\mathcal{M B B S}, \mathcal{M S}$

Professor, Department of Anatomy

Maulana Azad Medical College

Bahadur Shah Zafar Marg

New Delhi-110002

$I \mathcal{N} \mathcal{D} I \mathcal{A}$

Email: KumKumrana@hotmail.com

Received: 03-06-2006

Accepted: 27-07-2006 